\title{
Bei Gen-Veränderungen
}

\section{Hustenmittel gegen Parkinson?}

Bestimmten Parkinsonkranken könnte der Schleimlöser Ambroxol helfen: Bei Mutationen im Gen für Glukozerebrosidase verbessert die Substanz offenbar die Lysosomenfunktion. Davon würden vor allem Patienten mit raschem und schwerem Verlauf profitieren.

Bei den meisten Parkinsonkranken ist noch unklar, wodurch die Krankheit ausgelöst wird. Zwar gibt es eine ganze Reihe von Genmutationen, die zu einer familiären Parkinsonkrankheit führen, allerdings sind diese recht selten. Auf der anderen Seite kennen Forscher viele häufige Genvarianten, die das Parkinsonrisiko nur minimal erhöhen. Eine Zwischenstellung hat das Gen für Glukozerebrosidase (GBA): Je nach Variante wird das Parkinsonrisiko um das Drei- bis Fünfzehnfache gesteigert.

In Deutschland tragen etwa 3-4\% der Parkinsonkranken GBA-Mutationen, erläuterte Prof. Dr. Thomas Gasser vom Uniklinikum Tübingen. Solche Patienten unterscheiden sich zum Teil deutlich von Parkinsonkranken ohne auffälliges GBA-Gen: Sie sind zum Krankheitsbeginn jün-

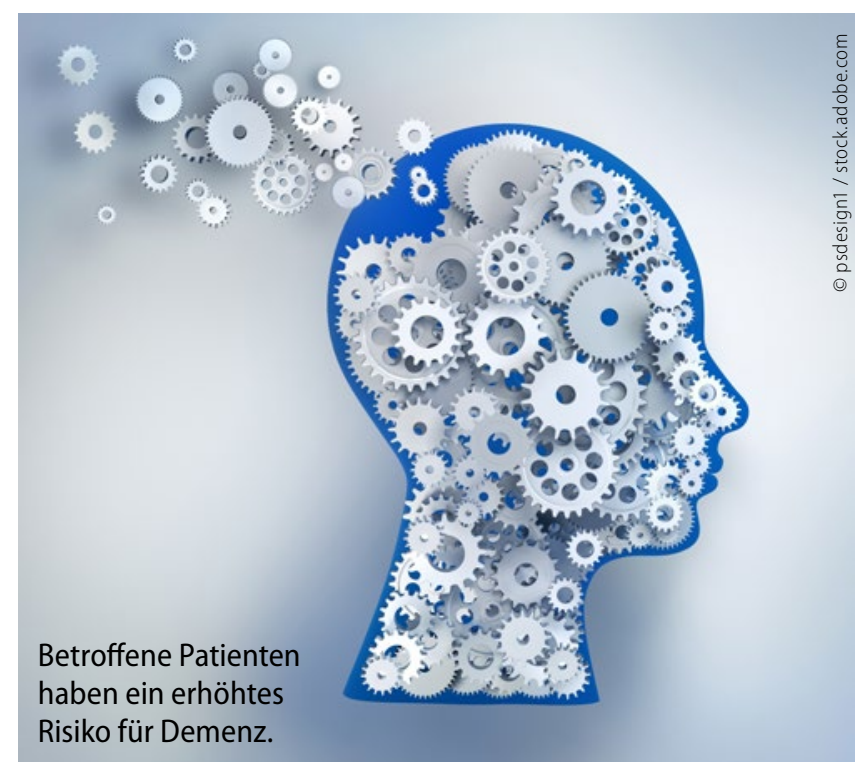

Glykosphingolipide unter anderem in Makrophagen und führen zur Speicherkrankheit Morbus Gaucher. Die „Gaucher-Zellen“ häufen sich in Leber, Milz oder Knochenmark - mit schwerwiegenden Folgen.

ckelt: Möglicherweise kann der Schleimlöser Ambroxol Parkinsonkranken mit GBA-Veränderungen helfen. In Zellkultur- und Tierexperimenten gelang es mit der Substanz, die GBA-Aktivität zu steigern, vermutlich indem sie den Transport veränderter GBA-Moleküle in die Lysosomen erleichtert, sagte Gasser. Noch in diesem Jahr sollen klinische Studien bei Patienten mit GBA-Veränderungen beginnen. Verlaufen diese erfolgreich, könnte die Gendiagnostik bei Parkinson einen ganz neuen Stellenwert gewinnen, ist der Neurologe überzeugt. Allein in Deutschland werden 10.000 Parkinsonkranke mit GBA-Veränderungen vermutet.

\section{Genvariante entscheidet} über Therapieerfolg

Doch auch bei der dopaminergen Therapie sind bestimmte Genvarianten für den Therapieerfolg relevant. Gasser verwies auf eine Nachauswertung der ADAGIOStudie mit Rasagilin, bei der Ansprechraten unter verschiedenen Varianten für Dopamin-Rezeptoren analysiert wurden. So sprachen Patienten mit bestimmten Verändeger, die Krankheit verläuft schneller und sie entwickeln häufiger nichtmotorische Beschwerden. Nach Daten einer Analyse bei knapp 3000 Parkinsonkranken haben Patienten mit GBAVeränderungen ein verdreifachtes Demenzrisiko, zudem sterben sie wesentlich früher, sagte Gasser auf der Fortbildungsveranstaltung Neuro Update in Mainz.

\section{Parkinsonvariante mit M. Gaucher verwandt}

Interessant sind GBA-Mutationen auch deshalb, weil die Funktion des Proteins gut bekannt ist. Es ist nötig, um Cerebroside in den Lysosomen abzubauen. Klappt das nicht mehr, sammeln sich die

Schon vor hundert Jahren ist Ärzten aufgefallen, dass Eltern von GaucherKindern häufig an Parkinson erkranken. Offenbar haben die veränderten Proteine auch bei heterozygoten Genträgern einen negativen Effekt. Dabei wird angenommen, dass GBA nicht mehr gut in die Lysosomen gelangt und sich dort nicht am Abbau verklumpter Proteine beteiligen kann. Dies führt wohl insgesamt zu dysfunktionalen Lysosomen und erschwert den Abbau von pathologisch gefaltetem Alpha-Synuclein in Nervenzellen.

Aus diesen Erkenntnissen haben Forscher einen neuen Therapieansatz entwi- rungen im Dopamin-D2-Rezeptor kaum auf den MAO-B-Hemmer an, solche mit anderen Varianten wiederum sehr gut.

Mit diesem Wissen ließe sich durchaus die Pharmakotherapie optimieren. Gasser erinnerte daran, dass eine ExomAnalyse, also eine Sequenzierung aller kodierenden DNA-Abschnitte, heute für rund 2500 Euro zu haben ist. Solche Analysen könnten künftig entscheidend sein, um für den einzelnen Patienten die bestmögliche Therapie zu wählen.

Thomas Müller

Neuro Update, Mainz, 3.3.2017. Prof. Dr. Thomas Gasser, Tübingen: Neurogenetik 